\title{
Aparicio Durán, P. (2018). El discurso literario y su aplicación didáctica en el aula de E/LE. Propuestas de trabajo. Octaedro.
}

Horacio Molano Nucamendi

Centro de Enseñanza para Extranjeros Universidad Nacional Autónoma de México

Las bases de este libro se sustentan en un enfoque histórico de la enseñanza de las lenguas extranjeras. Por tal motivo, Pablo Aparicio Durán sitúa el debate teórico de la enseñanza de ELE como un espacio académico apropiado para incluir al texto literario en los materiales didácticos; con él, asegura el autor, se generará en los estudiantes una conciencia del momento que nos ha tocado vivir y las implicaciones individuales de ello.

En el volumen se explica la importancia de trabajar en el aula procesos que se han dejado de lado al adquirir la lengua materna, pues se han realizado de forma inconsciente. Al aprender una lengua extranjera, la persona se plantea el estudio de su coyuntura histórica, pues esta se manifiesta en forma de discurso, lo que hace visibles las marcas de orden sociocultural que son indispensables para comprender y hacer uso pleno de ese idioma. Entenderse a sí mismo en otro orden espacial conlleva la conciencia crítica del trasfondo ideológico de las manifestaciones lingüísticas.

¿Qué se moviliza en la percepción del estudiante durante el proceso de enseñanza- aprendizaje de una lengua extranjera? Pablo Aparicio nos comparte su enfoque al colocar en un primer plano el componente cultural que implica la adquisición de una LE, pues para él "no es que la lengua sea expresión de una cultura, sino al revés: la cultura es la expresión de una lengua, es decir, del discurso" (130). Por consiguiente, nos dice el autor, es relevante tener la oportunidad de incluir en un programa de estudios el concepto de "radical historicidad" de Rodríguez (2001), que distingue los distintos modos de producción por los cuales ha transitado la humanidad, o, cuando menos, la civilización europea, a saber: las relaciones sociales entre amo/esclavo, señor/ siervo y sujeto/sujeto, relaciones que marcan tres etapas bien delimitadas conocidas como esclavismo, feudalismo y capitalismo. En esta última etapa se considera libre e igual a ese sujeto que crea un vínculo contractual con otro, lo cual da sustento a una visión moderna de nuestro tiempo. Aparicio Durán nos recuerda que desde el esquema del materialismo histórico se plantea una lucha de clases entre la burguesía y el proletariado, por lo que ese "sujeto en libertad" podría cuestionarse. Sin embargo, sostiene, lo importante a tomar 
en cuenta es el tipo de discurso ideológico que se sitúa detrás de cada modo de producción: la política que somete al individuo al imperio, la religión que legitima un organicismo sacralizado o el capital que rige un orden económico. Estar conscientes del momento en el cual se ubica un texto literario es fundamental para incitar al análisis de la dimensión histórica de la lengua.

Por otra parte, el autor señala que no hay didáctica general, sino que existen didácticas específicas determinadas por las áreas de conocimiento en que se aplican. De este modo, en la didáctica de LE cobra importancia el papel de un profesorado activo y crítico, ya que:

la clase de idiomas es una situación privilegiada, pues quizá sea el lugar donde los presupuestos culturales (y lo son justamente al pretender ser cuestionados o reafirmados solo en lo que tienen de cultural) se vuelven más explícitos e identificables, debido a la necesidad del docente (necesidad plasmada sobre todo en los libros de texto) de plantear y dirigir los temas para crear situaciones comunicativas, es decir, para poder hablar de lo que hacemos, pensamos, sabemos, queremos, etc. (Aparicio, 2018: 66).

Considero sustancial esta observación, pues en el aula de ELE, sobre todo en un contexto universitario -espacio de reflexión y crítica-, tenemos la posibilidad de analizar las circunstancias de hechos sociales para coadyuvar a la formación del estudiante como un ciudadano del mundo. De allí que el empleo del texto literario sea clave como manera de despertar la conciencia histórica del discente.

En otras palabras, para el profesor de ele la cultura es la expresión de una lengua de la cual se enseñan significados y funciones (verbales y no verbales), a la par que se exploran los sentidos (los límites y las contradicciones). El autor considera a la literatura como la materialización de una lengua a través de la cual se llega a aprendizajes eficaces y se devela el "inconsciente ideológico" (término también de Rodríguez (2010), citado por Aparicio Durán), con el cual, según Althusser (1975), se pone en juego un conjunto de ideas compartidas sobre la manera en la que se llevan a cabo el aprendizaje, el crecimiento y el desarrollo de la gente. Es por ello que señalamos nuevamente el primer plano que ocupa el docente de eLE al seleccionar los textos adecuados con los cuales trabajar en clase y plantear el claro objetivo de llegar al nivel "radicalmente histórico". Aparicio lo ejemplifica en su libro con secuencias didácticas que toman en consideración, inicialmente, un nivel subjetivo y otro objetivo mediante los cuales el estudiante de ele será capaz, primero, de comentar libre y espontáneamente su postura ante determinado asunto o tema y de asociar ideas según su sensibilidad y creatividad; luego, se aproximará al saber mismo 
de la lengua mediante actividades relacionadas con la gramática, el léxico, la pragmática o la retórica.

Además de exponer con claridad el marco teórico en el cual se inserta, el autor ilustra su propuesta mediante una tabla informativa en la que desarrolla el tema de Ramón Gómez de la Serna y las greguerías, al cual le dedica siete sesiones de noventa minutos, lo que suma diez horas y media. Antes de presentar la unidad didáctica, Aparicio anota lo sustancial de diferenciar entre la literatura como asignatura en un plan de enseñanza de ele y la literatura como recurso para trabajar elementos lingüísticos y pragmáticos en el aula de ELE. Sin duda, en este caso se piensa en la primera, aunque, desde mi punto de vista, se extiende demasiado para cumplir con la revisión de la obra del escritor vanguardista español.

Por otro lado, se ubican las actividades en un nivel C2 del Marco Común Europeo de Referencia (MCER), lo cual reduce el empleo de textos literarios en el acompañamiento transversal de la adquisición de la lengua. En mi experiencia, el docente puede proponer clases de literatura para niveles intermedios, desde B1. La clave de su aprovechamiento está en la selección de los materiales de lectura. Los géneros más asequibles son las crónicas, el cuento y las minificciones. Textos cortos a los que se puede volver las veces necesarias para clarificar su comprensión e interpretación. Otro factor primordial, por supuesto, radica en el rol del profesor, quien activará un tópico generativo que aproveche la potencialidad expresiva del texto literario.

Sin embargo, Pablo Aparicio Durán recurre al cliché de trabajar con Como agua para chocolate de Laura Esquivel, al proponer actividades de refuerzo para B2. Considero que, si se trata de activar la conciencia histórica de los estudiantes de ELE, se tendría que seleccionar textos más complejos como los de Rosario Castellanos o Elena Garro, por mencionar a dos de las autoras más reconocidas del siglo xx en México. La razón que se arguye para utilizar a Esquivel es que Como agua para chocolate está presente "en todos los planes de estudios de los llamados 'A levels' en el Reino Unido"; asimismo, porque ejemplifica de manera directa la problemática social del patriarcado y del colonialismo. Me parece que, por eso mismo, se debe sugerir el estudio de otras autoras que con anterioridad ya venían discutiendo esos temas desde una propuesta literaria más consolidada. Propongo no recurrir a lo que ya se tiene probado, sino buscar textos distintos que provoquen el interés de los estudiantes de ELE.

Además, el propio autor no es claro con referencia al manejo del canon en la selección de lecturas para los programas de ELE, pues si bien refiere un valor intrínseco de los clásicos porque generan un mensaje universalmente humano y plantea que desde los estudios culturales se ha forzado una apertura al cuestionar la marginación desde el poder, ya sea por colonialismo, machismo, 
racismo o heterosexualidad, no hace explícito su criterio para elegir un texto literario en lugar de otro. Al seleccionar las lecturas de sus propuestas de trabajo elige, por ejemplo, El Quijote. Esta decisión genera debate, pues no se trata simplemente de despedirse de los "viejos" textos, sino de analizar la pertinencia de unos más acordes a los intereses de los estudiantes y a los propósitos de los docentes. Mostrar una tradición se convierte en un objetivo, por lo que Cervantes entra dentro de ese plan, pero, desde mi perspectiva, el caso de Laura Esquivel se aleja de esa concepción, pues no considero que su libro sea un clásico.

Al inicio de la presentación de sus series didácticas, el autor indica que la clase de ele debe definirse como "provechosa, cómoda, estimulante y ambiciosa" (Aparicio, 2018: 65) para conseguir la satisfacción del alumnado. Por ello, me parece que el criterio de selección de los textos literarios debe sustentarse en estimular intelectualmente y en proponer retos de conocimiento. Así, resulta sugerente volver a los planteamientos teóricos del propio Aparicio, quien propone la consideración del discurso literario desde un ángulo que va más allá del lingüístico, para propiciar en clase el manejo de categorías que sitúan al estudiante de ele en un proceso de autoexamen. De tal modo, tanto el docente como el discente se ubicarían como seres sociales en tiempos en los que prevalecen los valores capitalistas.

\section{REFERENCIAS}

Althusser, L. (1975). Curso de filosofía para científicos. Laia.

Rodríguez, J.C. (2001). La norma literaria. Debate. 